\title{
Histochemical, clinical, and in vitro $\beta$ cell responses in a neonate with persistent hyperinsulinaemic hypoglycaemia of infancy
}

\author{
N S Panesar, C W Poon, C T Liew, G W K Wong, N M Hjelm
}

The immunohistochemistry data were presented at the 16 th International Congress of Clinical Chemistry, London, 8-12 July 1996 and the case was presented at the 9th Asian Congress of Paediatrics, Hong Kong, 23-27 March 1997.

Department of Chemical Pathology, The Chinese University of Hong Kong,

Shatin, New

Territories, Hong Kong, People's Republic of China

N S Panesar

C W Poon

N M Hjelm

Anatomical and Cellular Pathology C T Liew

Department of

Paediatrics

G W K Wong

Correspondence to: Dr Panesar.

Email:

nspanesar@cuhk.edu.hk

Accepted 11 February 1998

\begin{abstract}
When treatment with diazoxide and somatostatin for persistent hyperinsulinaemic hypoglycaemia of infancy failed, subtotal pancreatectomy was performed on a neonate on day 41 . The pancreatic tissue was saved and used for immunohistochemical and cell culture studies. The initial immunohistochemistry of $\beta$ cells for insulin was negative, using a 1 in 200 dilution of insulin antiserum, but positive results were obtained with an increased concentration of the antiserum.
\end{abstract}

The insulin to somatostatin cell ratio in islets of Langerhans was about $1: 1$, with no somatostatin cells outside the islets. Glucose stimulated insulin secretion in a concentration dependent manner in vitro. Isobutyl methyl xanthine doubled insulin secretion, but lithium had no effect. The glucose stimulated insulin secretion was inhibited by somatostatin, epinephrine, and in the absence of $\mathrm{Ca}^{2+}$.

In view of the normal in vitro responses of $\beta$ cells to various secretory analogues, the lack of responsiveness to somatostatin analogue before pancreatectomy may not have been due to deficiency or resistance to somatostatin, but to $\beta$ cell hyperplasia overwhelming the paracrine regulatory mechanism(s).

(Arch Dis Child Fetal Neonatal Ed 1998;79:F141-F144)

Keywords: persistent hyperinsulinaemic hypoglycaemia of infancy; somatostatin; in vitro cell studies; negative immunohistochemistry; steric hindrance

The exact pathophysiology of excessive insulin secretion in persistent hyperinsulinaemic hypoglycaemia of infancy (PHHI) is complex and incompletely known. ${ }^{12}$ It may be associated with $\beta$ cell hyperplasia-nesidioblastosis. ${ }^{3}$ It might represent the persistence of fetal unresponsiveness to glucose. ${ }^{4}$ In the familial form of PHHI, which has an incidence of 1 in 2500, the defect lies in the sulphonylurea receptor, particularly in the $\mathrm{K}_{\text {AтP }}$ channels which remain permanently closed (and unresponsive to glucose), causing sustained depolarisation of $\beta$ cell membranes and opened calcium channels. The increase in cytosolic calcium triggers incessant insulin secretion. ${ }^{5}$ The involvement of calcium in the release of insulin has led to the use of calcium channel inhibitors to treat PHHI. ${ }^{6}$ Diazoxide inhibits insulin release by opening the $\mathrm{K}_{\mathrm{ATP}}$ channels. ${ }^{5}$ PHHI may also be caused by a lack of inhibitory paracrine control by somatostatin ${ }^{7}$; the somatostatin analogue has also been used in its treatment. Neonates who fail to respond to drug treatment inevitably require partial pancreatectomy to control the adverse effects of hyperinsulinism.

The incidence of the sporadic form of PHHI is reported to be 1 in $50000,{ }^{5}$ but the incidence among the Chinese population is not known. We report a case of a Chinese neonate who presented with PHHI, and after failing to respond to conventional treatment, underwent subtotal pancreatectomy on day 41 . The pancreatic cells were cultured and their responses to various inhibitors and stimulants tested in vitro, with the aim of determining whether the cause of the PHHI was attributable to breakdown of paracrine regulation of the $\beta$ cells or unresponsiveness to somatostatin.

\section{CASE REPORT}

A full term boy weighing $3.3 \mathrm{~kg}$, the first child of non-consanguineous parents, was delivered after an uneventful pregnancy. He was admitted to the neonatal unit 6 hours later because of apnoea and cyanosis. Blood glucose was 1.6 $\mathrm{mmol} / \mathrm{l}$ and intravenous glucose infusion was started at $6 \mathrm{mg} / \mathrm{kg} / \mathrm{min}$. He developed repeated episodes of bradycardia associated with twitching of limbs and his serum glucose was 1 $\mathrm{mmol} / \mathrm{l}$ and less than $0.1 \mathrm{mmol} / 1$ on two other occasions. The intravenous glucose infusion was gradually increased to over $20 \mathrm{mg} / \mathrm{kg} / \mathrm{min}$ before optimal glycaemia could be maintained. Serum insulin concentrations obtained on several occasions when the patient's serum glucose was below $2 \mathrm{mmol} / 1$ were in the range of 7-11 mU/1. Serum growth hormone and cortisol concentrations were greater than 30 $\mathrm{mU} / \mathrm{l}$ and $500 \mathrm{nmol} / \mathrm{l}$, respectively, when the patient was hypoglycaemic.

Oral diazoxide was started on day 14 at 14 $\mathrm{mg} / \mathrm{kg} /$ day in three divided doses, increasing to $18 \mathrm{mg} / \mathrm{kg}$ /day by day 17 . Octreotide (somatostatin analogue; Sandoz) was added on day 20 at $13 \mu \mathrm{g} / \mathrm{kg} /$ day in three divided doses given subcutaneously. This was stepped up gradually to a dose of $34 \mu \mathrm{g} / \mathrm{kg} /$ day. Hydrochlorothiazide was added to control the water retention induced by diazoxide. Despite combination treatment, the infant continued to require intravenous glucose infusion in excess of 15 $\mathrm{mg} / \mathrm{kg} / \mathrm{min}$ to maintain serum glucose over 3 $\mathrm{mmol} / \mathrm{l}$. It was not possible to start milk feeding and maintain optimal glycaemia. A 95\% pancreatectomy was performed on day 41 and the resected pancreatic tissue was processed for immunohistochemistry and in vitro cell culture 


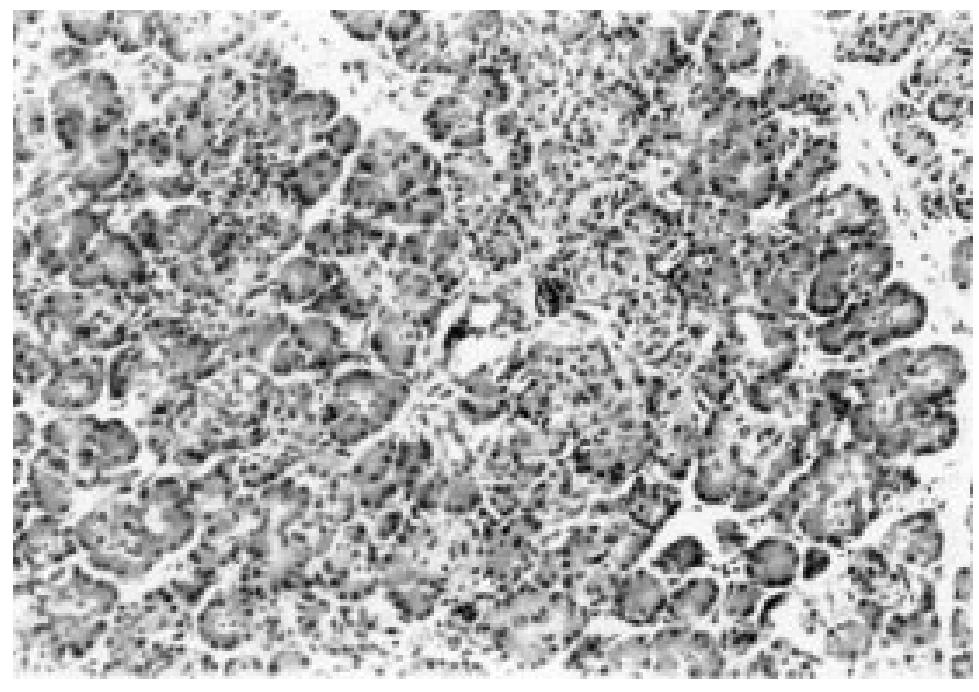

Figure 1 Haematoxylin and eosin staining showing loose and diffuse distribution of pale staining serous cells in a section of the pancreas from a neonate with nesidioblastosis. Cells are not clustered into discrete islets of Langherans. Darker staining cells show eosinophilic cytoplasm with centro-acinar cells forming the acinus.

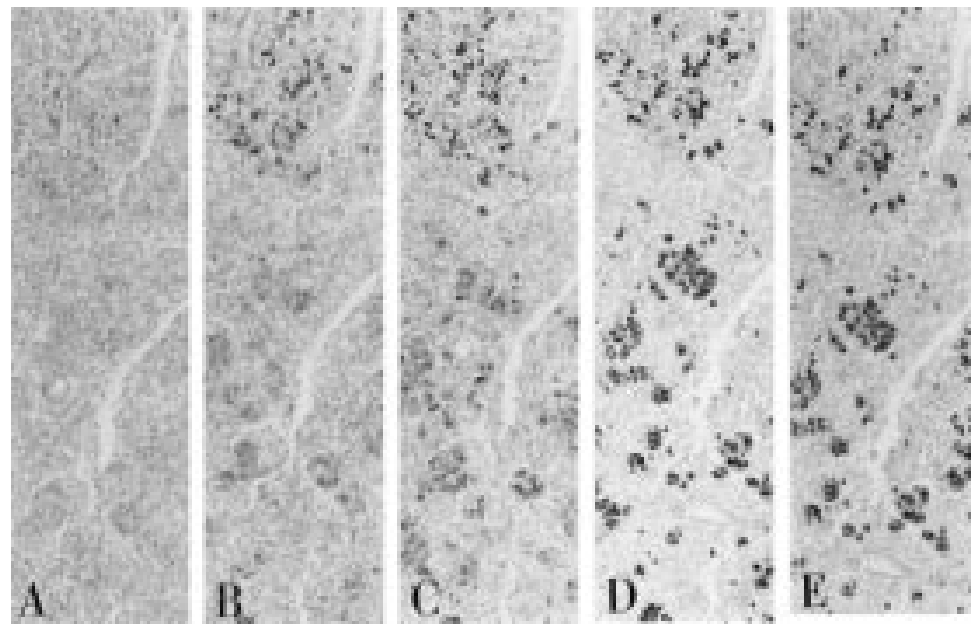

Figure 2 Montage showing immunohistochemical staining for insulin in the same pancreatic section at various dilutions of primary insulin antiserum: (A) 1 in 200; (B) 1 in 100; (C) 1 in 50; (D) 1 in 20; and (E) undiluted serum.

experiments. Postoperatively, optimal glycaemia was maintained and the glucose requirement dropped to below $10 \mathrm{mg} / \mathrm{kg} / \mathrm{min}$. Milk feeds were started and glucose infusion was gradually reduced. The infant was able to tolerate full feeds and maintain a serum glucose over $3 \mathrm{mmol} / \mathrm{l}$ and was discharged on day 99. The parents were instructed to perform glucose monitoring daily.

A few days after discharge the baby was admitted again because of hypoglycaemia with concentrations in the range of $2-3 \mathrm{mmol} / 1$ before feeding. Blood glucose concentrations in the hospital were between 1.2 to $1.9 \mathrm{mmol} / 1$ with inappropriately high insulin concentrations. Subcutaneous octreotide treatment was restarted at $9 \mu \mathrm{g} / \mathrm{kg} / \mathrm{min}$, increasing to 20 $\mu \mathrm{g} / \mathrm{kg} /$ day whereby serum glucose could be maintained over $3.5 \mathrm{mmol} / 1$. The patient is now 2 years old and continues to receive octreotide treatment without clinically significant side effects. The child's neurodevelopment is within normal limits for a 2 year old.

\section{Methods}

Somatostatin, epinephrine, collagenase (type IX), isobutyl methyl xanthine (IBMX), lithium chloride, Hanks' Balanced Salt Solution (HBSS) with and without calcium and magnesium, and culture were obtained from Sigma Chemical Co. (St Louis, MI, USA). RPMI 1640, fetal calf serum (FCS) and trypsinEDTA were obtained from Gibco (Gaithersberg, MD, USA). All antisera for immunohistochemistry were obtained from Dako (Glostrup, Denmark), with the exception of chromogranin which was obtained from BioGenex (San Ramon, CA, USA).

\section{IMMUNOHISTOCHEMISTRY OF THE PANCREAS}

One half of the resected pancreas was immediately fixed in $10 \%$ buffered formalin and embedded in paraffin wax for determining cell types and their hormonal secretions. For immunohistochemical studies, all the sections were first treated with the microwave antigen retrieval method, ${ }^{8}$ followed by immunohistochemistry, using the routine avidin-biotin method (ABC) and the peroxidase antiperoxidase method (PAP). A panel of endocrine and non-endocrine tissue markers were used as positive controls (antiserum dilutions routinely used are in parentheses): $\alpha_{1}$ antitrypsin ( 1 in 300), chromogranin (neat), gastrin (1 in 250), glucagon (1 in 300), neuron specific enolase (1in 150) and somatostatin (1in 300). The insulin antiserum was initially used at 1 in 200 dilution. Before using ABC or PAP, endogenous peroxidase in the tissue was blocked using 3\% aqueous hydrogen peroxide for 5 minutes. The ABC method was performed as follows: incubation with the primary mouse anti-human antibodies; incubation with biotinylated rabbit anti-mouse immunoglobulins; incubation with $\mathrm{ABC}$ complex; development in 3,3'- diaminobenzidine solution; and counterstained lightly with Meyer's haematoxylin. For each of the above steps the sections were first rinsed in three changes of TRIS buffer. Twenty high power fields were counted for insulin and somatostatin positive cells, within and outside islets of Langerhans. Positive reaction was indicated by a brown colour.

CELL CULTURE AND IN VITRO EXPERIMENTS About $0.2 \mathrm{~g}$ of freshly excised pancreatic tissue was cut into $2 \mathrm{~mm}$ blocks and gently digested with collagenase in HBSS containing $2 \%$ FCS. The dispersed tissue was cultured in RPMI 1640 containing $10 \%$ FCS for 60 hours as a primary cell culture. The cells were diluted with $0.025 \%$ trypsin containing EDTA in HBSS without calcium and magnesium. The cells were resuspended in RPMI 1640 culture medium and 30000 cells plated per well of a 24 well culture plate.

Three days after setting up the cultures the cells were preincubated in HBSS-HEPES buffer comprising: $137 \mathrm{mmol} / 1 \mathrm{NaCl}, 5 \mathrm{mmol} / 1$ $\mathrm{KCl}, 0.44 \mathrm{mmol} / 1 \mathrm{KH}_{2} \mathrm{PO}_{4}, 0.337 \mathrm{mmol} / 1 \mathrm{Na}_{2}$ $\mathrm{HPO}_{4}, 1 \mathrm{mmol} / 1 \mathrm{MgSO}_{4}, 2 \mathrm{mmol} / 1 \mathrm{CaCl}$ (excluded for experiment on the effect of $\mathrm{Ca}^{2+}$ ), $0.035 \% \mathrm{NaHCO}_{3}$ and $5 \mathrm{mmol} / 1 \mathrm{HEPES}$ without glucose for 1 hour at $37^{\circ} \mathrm{C}$ in $5 \% \mathrm{CO}^{2}$. 


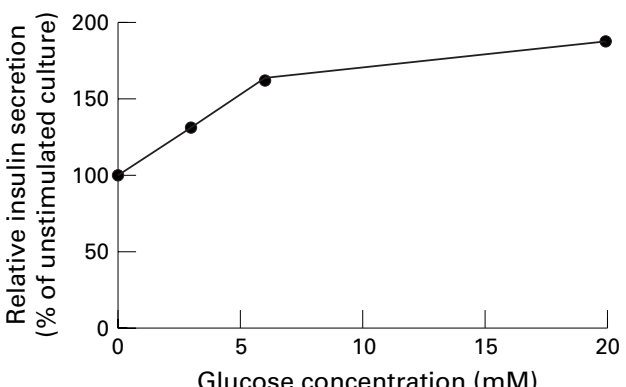

Figure 3 Mean $(n=2)$ secretion of insulin by cultured pancreatic cells in response to different concentrations of glucose.

After aspirating the medium, the cells were incubated in HBSS-HEPES without glucose but containing $0.5 \%$ bovine serum albumin for 100 minutes at $37^{\circ} \mathrm{C}$ to determine the basal insulin release. The medium was carefully removed, centrifuged at $240 \times g$ for 10 minutes and stored at $-40^{\circ} \mathrm{C}$ until assayed for insulin. The insulin release was then studied in response to: $0,3,6$ and $20 \mathrm{mmol} / 1$ of glucose; $0.5 \mathrm{mmol} / 1 \mathrm{IBMX}$ with and without $10 \mathrm{mmol} / 1$ lithium chloride; absence of $\mathrm{Ca}^{2+}$ in the incubation medium, with and without 6 $\mathrm{mmol} / 1$ glucose as the stimulant; and 6 and 600 $\mathrm{nmol} / 1$ somatostatin and 60 and $6000 \mathrm{nmol} / 1$ epinephrine, with and without $6 \mathrm{mmol} / 1$ glucose as the stimulant. The incubations were performed for 1 hour at $37^{\circ} \mathrm{C}$ in duplicate. At the end of incubation period the medium was harvested and stored at $-40^{\circ} \mathrm{C}$ until assayed for insulin using an Abbott IMx microparticle enzyme immunoassay (Abbott Park, Chicago, IL, USA).

\section{Results}

HISTOLOGICAL FINDINGS

Gross examination of the specimen showed a partially resected pancreas with smooth parenchyma and intact lobules. No nodules were present. Haematoxylin and eosin staining showed $\beta$ cell hyperplasia with small clusters of loose cells, with clear cytoplasm diffusely distributed throughout the pancreas. These cells were somewhat accentuated around or near the ducts (fig 1). Immunohistochemical staining at various dilutions of insulin antiserum is shown in fig 2. Immunohistochemistry of $\beta$ cells for insulin was positive at neat and 1 in 20 dilutions; faintly positive at 1 in 50 and 1 in 100 dilutions, and negative at 1 in 150 and 1 in 200 dilutions. The brown stain was localised in the cytoplasm of the clear cells with minimal non-specific background staining. All other tissue markers were positive at the routinely used dilutions of the respective antisera (results not shown). The ratio of insulin to somatostatin cells in islets of Langerhans was about 1:1. Only discrete insulin secreting cells were observed outside the islets (data not shown).

IN VITRO RESPONSES OF PANCREATIC CELLS

The dependence of insulin release by pancreatic cells on the glucose concentration is shown in fig 3. The release almost doubled at a glucose concentration of $20 \mathrm{mmol} / 1$ (fig 3 ) or in the presence of IBMX (preserver of cAMP)

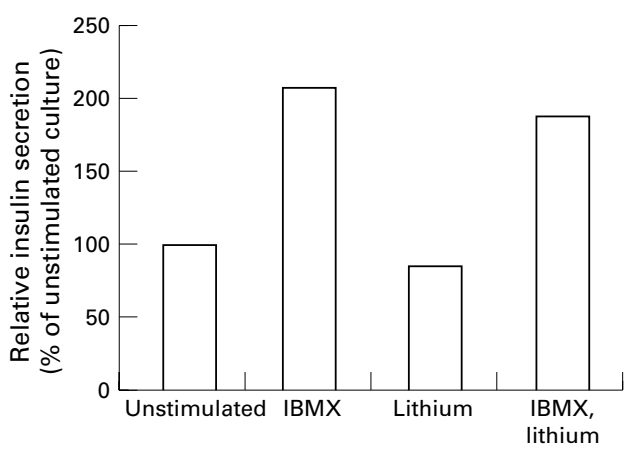

Figure 4 Mean $(n=2)$ secretion of insulin in the absence or presence of IBMX, lithium, or both, by cultured pancreatic cells.

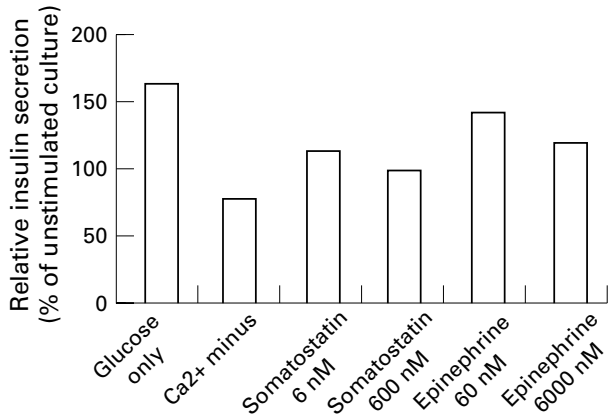

Figure 5 Mean $(n=2)$ secretion of insulin stimulated by 6 mmolll glucose in the absence of $\mathrm{Ca}^{2+}$, presence of 6 or 600 nmolll somatostatin, or presence of 60 or $600 \mathrm{nmol} / \mathrm{l}$ epinephrine.

(fig 4). However, lithium, which preserves inositol triphosphate, had no effect (fig 4). With $6 \mathrm{mmol} / \mathrm{l}$ glucose as the stimulant, exclusion of $\mathrm{Ca}^{2+}$ from incubation medium resulted in an almost $50 \%$ decrease in insulin release. Somatostatin and epinephrine decreased the stimulatory effects of glucose on insulin release, in a concentration dependent manner (fig 5).

\section{Discussion}

This case presented with hypoglycaemia and inappropriately high insulin secretion. Histological examination of pancreatic tissue showed endocrine cell dysplasia with increased insulin content, all characteristic of PHHI. ${ }^{9} 10$ The ratio of cells staining for insulin and somatostatin in this study (1:1) was different from that of a previous report, where the ratio was 5:1 (in an unspecified region of the pancreas) and somatostatin deficiency was thought to be the cause of the nesidioblastosis. ${ }^{9}$ The apparent hyperplasia of somatostatin cells in islets may have resulted from hyperinsulinaemia from $\beta$ cells outside the islets. Therefore, somatostatin may have maintained paracrine inhibition of $\beta$ cells in islets, thus reducing the $\beta$ to $\delta$ cell ratio from $2: 1^{9}$ (normal) to $1: 1$. However, $\beta$ cells outside the islets may not have been amenable to such inhibitory regulation, hence the hyperinsulinaemia.

The maximum insulin response related to the glucose concentration in the incubation medium $(20 \mathrm{mmol} / \mathrm{l})$ was similar to that of one study, ${ }^{7}$ but differed from other investigations, 
where lack of response in some cases ${ }^{4}$ and a maximum response at $4 \mathrm{mmol} / 1$ of glucose has been reported. ${ }^{9}$ The variable insulin response to glucose probably reflects a spectrum of maturity state of $\beta$ cells in PHHI. The unresponsive cells are probably less mature fetal type cells, ${ }^{4}$ whereas the responsive cells are the more mature neonatal type cells. The in vitro inhibition of insulin release by somatostatin and the postoperative response to it also suggests that cells were capable of responding to somatostatin. Although Otonkoski et al concluded that PHHI is caused by the deficiency of islet somatostatin, in our case PHHI probably resulted from loss of inhibitory paracrine control of somatostatin by sheer mass of $\beta$ cells. Insulin release was also inhibited by epinephrine, which is a known counter regulatory hormone. Incubation with IBMX, a blocker of the cAMP degradation pathway, doubled the insulin release, whereas lithium did not stimulate the release of insulin. The latter finding suggests that the inositol triphosphate second messenger system is not involved, although the phosphoinositide protein kinase $\mathrm{C}$, operating via the diacylglycerol pathway, has been implicated in the release of insulin. ${ }^{4}$ The dependence of insulin release on calcium and its abolishment in the absence of the ion was also a normal response.

Therefore, in all respects the patient's $\beta$ cells responded normally to stimulatory (glucose and cAMP) and inhibitory (somatostatin, epinephrine, and lack of calcium) stimuli in vitro.

It is well established that the proportion of antibodies used in immunoassays will have to be proportional to the amount of antigeninsulin -in the sample. Too much antigen compared with the amount of antibodies will produce a false negative result from steric hindrance, and this has sometimes been called the "hook effect." 11 The initial negative result for insulin, when a section of the patient's pancreas was analysed, indicates that this effect is also present in immunohistochemical analysis. There are reports of this possibility, with a recommendation to reduce the antibody concentration to overcome false negative results. ${ }^{12}$ This contradicts the principle of an antibodyantigen reaction, where the antibody concentration should be increased to detect higher concentrations of an antigen-that is, "decreasing the sensitivity of an immunoassay." 13 Our own findings agree with this principle as the insulin reaction became positive by increasing the insulin antibodies well above the recommended amount. This result would indicate a substantially increased insulin concentration in the pancreatic tissue from the patient.

It is unlikely that the initial false insulin immunohistochemistry result was caused by depletion of insulin from the pancreas before surgery. ${ }^{14}$ Pancreatic cells cultured for three days secreted large amounts of insulin and pre- vious reports have also shown increased insulin concentrations in pancreatic tissue from patients with nesidioblastosis or insulinomas. ${ }^{915}{ }^{16}$ Methodological factors can give variable results in immunohistochemistry. ${ }^{17}$

In conclusion, the $\beta$ cells of the neonate responded like normal $\beta$ cells in vitro. The poor response to octreotide in vivo before pancreatectomy may not have been due to the resistance of $\beta$ cells to somatostatin or lack of it, but that $\beta$ cell hyperplasia overwhelmed the regulatory mechanism/s. How the $\beta$ cell hyperplasia is triggered in the first place, however, is still not known. Moreover, negative immunohistochemistry results should be interpreted with caution, when using a single dilution of antiserum, because of possible steric hindrance of the antibody-antigen reaction from antigen excess in tissue sections.

The chemicals and reagents used in the in vitro studies were purchased with a grant to Dr N S Panesar from the Croucher Foundation.

1 Daneman D, Ehrlich RM. The enigma of persistent hyperinsulinemic hypoglycemia of infancy. 7 Pediatr 1993;123:573-5

2 Milner RD. Nesidioblastosis unravelled. Arch Dis Child 1996;74:369-72.

3 Gould VE, Memoli VA, Dardi LE, Gould NS. Nesidiodysplasia and nesidioblastosis of infancy: ultrastructural and immunohistochemical analysis of islet cell alterations with and without associated hyperinsulinaemic hypoglycaemia. and without associated hyperinsulinaemic hyp 7 Gastroenterol 1981;70(Suppl): 129-42.

4 Kaiser N, Corcos AP, Tur-Sinai A, et al. Regulation of insulin release in persistent hyperinsulinaemic hypoglycaemia of infancy studied in long-term culture of pancreatic tissue. Diabetologia 1990;33:482-8.

5 Dunne MJ, Kane C, Shepherd RM, et al. Familial persistent hyperinsulinemic hypoglycemia of infancy and mutations in the sulfonylurea receptor. N Engl F Med 1997;336:7036

6 Lindley KJ, Dunne MJ, Kane C, et al. Ionic control of beta cell function in nesidioblastosis. A possible therapeutic role for calcium channel blockade. Arch Dis Child
1996;74:373-8.

7 Otonkoski T, Andersson S, Simell O. Somatostatin regulation of beta-cell function in the normal human fetuses and in neonates with persistent hyperinsulinemic hypoglycemia. F Clin Endocrinol Metab 1993;76:184-8.

8 Cattoretti C, Suurmeijer AJH. Antigen unmasking on formalin-fixed paraffin-embedded tissue using microformalin-fixed paraffin-embedded tissue usin

9 Aynsley-Green A, Polak JM, Bloom SR, et al. Nesidioblastosis of the pancreas: definition of the syndrome and the sis of the pancreas: definition of the syndrome and the
management of the severe neonatal hyperinsulinaemic management of the severe neonatal hyperinsulin
hypoglycaemia. Arch Dis Child 1981;56:496-508.

10 Jaffe R. The pancreas. In: Wigglesworth JS, Singer DB, eds. Textbook of fetal and perinatal pathology. Boston: Blackwell Scientific, 1991:1021-55.

11 Edwards R. Immunoassay: An Introduction. London: William Heinemann Medical Books, London, 1985.

12 Bigbee JW, Kosek JC, Eng LF. Effects of primary antiserum dilution on staining of "antigenrich" tissues with the peroxidase antiperoxidase technique. 7 Histochem Cytochem 1977;25:443-7.

13 Chard T. An introduction to radioimmunoassay and related techniques. In: Work T S, Work E, eds. Laboratory methods in biochemistry and molecular biolog. Volume 6 Part 2. Amsterdam: Elsevier Biomedical Press, 1982.

14 Creutzfeldt W, Creutzfeldt C, Frerichs H, Track NS, Arnold R. Histochemistry, ultrastructure and hormone content of R. Histochemistry, ultrastructure and hormone content of
human insulinomas. Hormone Metab Res 1976;Suppl 6:718.

15 Kohnert KD, K Fä, Odselius R, et al. Production of pro-insulin, C-peptide, and insulin in nesidioblastosis, focal islet-cell adenomatosis, and genuine insulinomas. A correlated radioimmunochemical, immunohistochemical, and ultrastructural investigation with particular regard to the occurrence of argyrophil and pro-insulin immunoreactive cells. Diabetes Res 1988;8:151-63.

16 Tasaka Y, Nakaya F, Matsumoto H, Odagiri R, Ohgawara $\mathrm{H}$, Omori Y. Tumor and serum levels of proinsulin and insulin in insulinoma patients. Endocr f 1993;40:245-8.

17 Lambkin HA, Mothersill CM, Kelehan P. Variations in immunohistochemical detection of p 53 protein overexpression in cervical carcinomas with different antibodies and methods of detection. $\mathcal{F}$ Pathol 1994;172:13-8. 